\title{
Changes in inhibition during differential eyeblink conditioning with increased training
}

\author{
Matthew M. Campolattaro, Kathleen M. Schnitker, and John H. Freeman \\ University of Iowa, Iowa City, Iowa
}

\begin{abstract}
Three experiments examined inhibitory learning in rats, using Pavlovian and differential inhibitory eyeblink conditioning procedures. Experiment 1 was designed to compare summation and retardation effects following Pavlovian conditioned inhibition $(\mathrm{A}+\mathrm{XA}-)$ or differential inhibition $(\mathrm{A}+/ \mathrm{X}-)$ training using auditory and visual conditioned stimuli (CSs). After ten 100-trial sessions of training, both Pavlovian conditioned inhibition and differential inhibition produced a retardation effect. However, a summation effect was obtained only for rats given Pavlovian conditioned inhibition training. Experiment 2 showed that increasing differential inhibition training to twenty 100-trial sessions produced summation and retardation effects. In Experiment 3, rats were trained with either ten or twenty 100-trial sessions of intramodal inhibitory training with two tone CSs ( $2 \mathrm{kHz} v \mathrm{ks} .8 \mathrm{kHz})$. Summation and retardation effects were obtained after only 20 sessions of differential conditioning. The findings indicate that extensive training is needed to establish conditioned inhibition with intermodal or intramodal differential conditioning.
\end{abstract}

Pavlovian conditioned inhibition and differential inhibition are examples of training methods that have been used to investigate inhibitory learning (e.g., Pavlov, 1927; Rescorla \& LoLordo, 1965; Urcelay \& Miller, 2006; Williams, Travis, \& Overmier, 1986). Acquisition of Pavlovian conditioned inhibition and acquisition of differential inhibition are typically achieved using discrimination training with two different types of intermixed training trials. In Pavlovian conditioned inhibition, a conditioned stimulus (CS) is consistently reinforced when presented by itself and is not reinforced when accompanied by a second CS $(\mathrm{A}+/ \mathrm{XA}-)$. Differential inhibition training uses presentations of reinforced CS trials and separate trials with a different $\mathrm{CS}$ that is not reinforced $(\mathrm{A}+/ \mathrm{X}-)$.

Summation and retardation tests have been used to directly compare inhibition produced by Pavlovian conditioned inhibition $(\mathrm{A}+/ \mathrm{XA}-)$ and differential inhibition $(\mathrm{A}+/ \mathrm{X}-)$ procedures. Pavlovian conditioned inhibition has been found to produce stronger (Rescorla, 1982; Urcelay \& Miller, 2006, Experiment 2), weaker (Urcelay \& Miller, 2006; Williams et al., 1986, Experiment 1), or the same amount of inhibition (Couvillon, Ablan, \& Bitterman, 1999; Jones \& Gonzalez-Lima, 2001; Mahoney, Kwaterski, \& Moore, 1975), relative to differential conditioning. It appears that neither training procedure consistently establishes stronger inhibition, and it is likely that numerous experimental variables determine which procedure produces larger summation and retardation effects.

Pavlovian conditioned inhibition and differential inhibition procedures have been shown to produce similar amounts of inhibition in nictitating membrane (NM) con- ditioning in rabbits (Mahoney et al., 1975). An open question is whether Pavlovian conditioned inhibition and differential inhibition produce similar amounts of inhibitory learning during eyeblink conditioning with rats. Previous inhibitory learning experiments in rodent eyeblink conditioning have used only Pavlovian conditioned inhibition procedures (Campolattaro \& Freeman, 2006; Freeman, Halverson, \& Poremba, 2005; Freeman \& Nicholson, 1999; Nicholson \& Freeman, 2002; Nolan \& Freeman, 2005, 2006). It may be expected that Pavlovian conditioned inhibition and differential inhibition procedures will produce similar amounts of inhibitory learning in eyeblink conditioning with rats because they have produced equal amounts of inhibitory learning in NM conditioning with rabbits (Mahoney et al., 1975). However, the summation test in Mahoney et al.'s study was conducted with two auditory CSs, and it is possible that the inhibitory tone CS that was used during discrimination may have generalized some inhibition to the previously conditioned excitatory white noise CS that was used for the summation test. This possibility makes it difficult to compare the relative effectiveness for producing summation effects between Pavlovian and differential inhibition conditioning.

The first experiment in the present study was designed to directly compare the effectiveness of Pavlovian conditioned inhibition and differential inhibition procedures for establishing inhibitory conditioning in rat eyeblink conditioning. Additional experiments examined whether the amount of discriminative conditioning was an important variable for establishing inhibitory conditioning during intermodal and intramodal differential inhibition training. 


\section{EXPERIMENT 1}

This experiment was designed to establish inhibitory learning to a light CS, using Pavlovian conditioned inhibition $(\mathrm{A}+/ \mathrm{XA}-)$ and differential inhibition $(\mathrm{A}+/ \mathrm{X}-)$ procedures. Following ten 100-trial sessions of discrimination training, summation and retardation tests were used to assess inhibition. The present experiment included control groups for the retardation test that determined the baseline rate for excitatory cross-modal transfer between auditory and visual CSs. These control groups for the retardation test have not previously been included in experiments on inhibitory eyeblink conditioning in rats (e.g., Campolattaro \& Freeman, 2006; Freeman et al., 2005; Freeman \& Nicholson, 1999; Nicholson \& Freeman, 2002; Nolan \& Freeman, 2005, 2006). A CS X-alone control group was also included in this experiment to determine whether any inhibition acquired by the putative inhibitory stimulus CS (X) during differential inhibition training was due to latent inhibition.

\section{Method}

Subjects. The subjects were 37 male Long-Evans rats (200-250 g), approximately 150 days old at the beginning of the experiment. The rats were housed in Spence Laboratories of Psychology at the University of Iowa with a 12:12-h light:dark cycle, with light onset at 07:00 a.m.

Surgery. One week prior to training, the rats were removed from their home cage and anesthetized by an intraperitoneal (i.p.) injection of sodium pentobarbital $(80 \mathrm{mg} / \mathrm{kg})$. An i.p. injection of atropine sulfate $(0.45 \mathrm{mg} / \mathrm{kg})$ was administered to reduce respiratory tract secretions. The rats were fitted with differential EMG electrodes that were implanted in the left upper eyelid muscle (orbicularis oculi), and a ground electrode was attached to a stainless steel skull screw. The EMG electrode leads terminated in gold pins held in a plastic connector, which was secured to the skull with dental acrylic. A bipolar stimulating electrode (for delivering the shock unconditioned stimulus [US]) was implanted subdermally, immediately caudal to the left eye. The bipolar electrode terminated in a plastic connector that was secured to the skull with dental acrylic.

Conditioning apparatus. The conditioning apparatus consisted of four small-animal sound attenuation chambers (BRS/LVE, Laurel, $\mathrm{MD}$ ). Within each sound attenuation chamber was a small-animal operant chamber (BRS/LVE) where the rats were kept during conditioning. One wall of the operant chamber was fitted with two speakers. The back wall of the sound attenuation chamber was equipped with a small house light and an exhaust fan. A light bulb (for delivering the light CS) was located on the back wall of the sound attenuation chamber, positioned directly behind the operant chamber. The electrode leads from the rat's headstage were connected to peripheral equipment and a desktop computer. Computer software controlled the delivery of stimuli and the recording of eyelid EMG activity (JSA Designs, Raleigh, NC). The shock US was delivered through a stimulus isolator (Model 365A, World Precision Instruments, Sarasota, FL). EMG activity was recorded differentially, filtered $(500-5000 \mathrm{~Hz})$, and integrated by equipment (JSA Designs) described in other reports (Freeman et al., 2005; Nicholson \& Freeman, 2002).

Conditioning procedure. The experimental design is illustrated in Table 1. The rats were assigned to a Pavlovian conditioned inhibition (PAV, $n=8$ ), differential inhibition (DIF, $n=8$ ), latent inhibition (LI, $n=7$ ), or retardation control (CON1, $n=7 ; \mathrm{CON} 2, n=7$ ) group. All the rats in this experiment received two phases of training (Phases 1 and 2) and two phases of testing (Phase 3 and 4). This four-phase procedure was designed to establish a light CS as a conditioned inhibitor for the rats in the PAV and DIF groups. The CON1 and CON2 control rats were given training identical to that for the PAV and DIF rats, except that they were never exposed to the light CS prior to Phase 4 testing. The control groups were necessary in order to match the rein- forcement history and number of presentations of A in both the PAV and the DIF groups. These control rats, therefore, provided a baseline rate for cross-modal transfer between a tone $\mathrm{CS}$ and a light $\mathrm{CS}$. Tone 1 $\left(\mathrm{T}_{1}\right)$ was a $2-\mathrm{kHz}$ tone; Tone $2\left(\mathrm{~T}_{2}\right)$ was an $8-\mathrm{kHz}$ tone; the light $\mathrm{CS}$ (L) was a 4-W light; and the US was a $25-\mathrm{msec} 1.0$ - to $2.0-\mathrm{mA}$ periorbital shock US. $\mathrm{T}_{1}$ and $\mathrm{T}_{2}$ were presented at $85 \mathrm{~dB}$. A plus sign (+) after a CS indicates that it was paired with the US; a minus sign (-) indicates that it was not paired with the US. The duration of each CS was $500 \mathrm{msec}$, with a $475-\mathrm{msec}$ interstimulus interval.

On each of the 10 days of Phase 1 training, the rats in the PAV group received a 100-trial session of Pavlovian conditioned inhibition training which consisted of $50 \mathrm{~T}_{1}+$ and $50 \mathrm{LT}_{1}-$ trials. This procedure has been used in previous studies to establish conditioned inhibition (Campolattaro \& Freeman, 2006; Freeman et al., 2005; Freeman \& Nicholson, 1999; Nicholson \& Freeman, 2002). The elements of the compound were presented simultaneously. The rats in the DIF group received a 100-trial session of differential inhibition training, which consisted of $50 \mathrm{~T}_{1}+$ and $50 \mathrm{~L}-$ trials. The rats in the LI group were given $50 \mathrm{~L}-$ trials only. The LI group was necessary for revealing whether latent inhibition (through preexposure) to the light stimulus alone can account for any inhibition acquired to the light CS. The rats in the CON1 control group were given $50 \mathrm{~T}_{1}+$ and $50 \mathrm{~T}_{1}-$ trials during Phase 1, whereas the rats in the CON2 control group were given $50 \mathrm{~T}_{1}+$ trials. Trials were separated by a variable intertrial interval that averaged $30 \mathrm{sec}$ (range, 18-42 sec). Phase 2 training was conducted the next day. On this day, all the rats except for those in the $\mathrm{LI}$ group received one 100 -trial session of $\mathrm{T}_{2}+$ training. The rats in the LI group received five 100 -trial sessions of $\mathrm{T}_{2}+$ training. The additional sessions of $T_{2}+$ given to the LI group were necessary to establish similar magnitude of conditioning to $\mathrm{T}_{2}$ observed in the other groups. For the rats in the PAV, DIF, and LI groups, Phase 3 (summation test) consisted of $30 \mathrm{~T}_{2}-$ and $30 \mathrm{LT}_{2}-$ trials, whereas the rats in the CON groups received $60 \mathrm{~T}_{2}-$ trials. All the groups were given Phase 4 training (retardation test) that consisted of one 100 -trial session of $\mathrm{L}+$. The summation and retardation tests were used to assess the amount of inhibition acquired by the inhibitory stimulus (Rescorla, 1969). These tests are necessary to show that the inhibitory stimulus is capable of attenuating conditioned responses (CRs) to an excitatory stimulus not used during the initial discrimination training (the summation test), as well as demonstrating difficulty when trained as an excitatory CS (the retardation test).

Eyelid EMG activity that exceeded a threshold of $0.4 \mathrm{~V}$ above the mean of the pre-CS activity was scored as a response. Responses that occurred during the first $80 \mathrm{msec}$ of the CS were scored as alpha (startle) responses. During CS-US trials, responses that occurred between the end of the alpha period and the onset of the US were scored

Table 1

Experimental Design Summary

\begin{tabular}{|c|c|c|c|c|}
\hline Group & Phase 1 & Phase 2 & Phase 3 & Phase \\
\hline \multicolumn{5}{|c|}{ Experiment 1: Pavlovian and Differential Inhibition } \\
\hline Pavlovian inhibition & $\mathrm{A}+/ \mathrm{XA}-$ & $\mathrm{B}+$ & $\mathrm{B}-/ \mathrm{XB}-$ & $\mathrm{X}+$ \\
\hline Differential inhibition & $\mathrm{A}+/ \mathrm{X}-$ & $\mathrm{B}+$ & $\mathrm{B}-/ \mathrm{XB}-$ & $\mathrm{X}+$ \\
\hline Latent inhibition & $\mathrm{X}-$ & $\mathrm{B}+$ & $\mathrm{B}-/ \mathrm{XB}-$ & $\mathrm{X}+$ \\
\hline Control 1 (retardation) & $\mathrm{A}+/ \mathrm{A}-$ & $\mathrm{B}+$ & $\mathrm{B}-$ & $\mathrm{X}+$ \\
\hline Control 2 (retardation) & $\mathrm{A}+$ & $\mathrm{B}+$ & B- & $\mathrm{X}+$ \\
\hline
\end{tabular}

Experiment 2: Differential Inhibition With Extended Training Differential inhibition $\mathrm{A}+/ \mathrm{X}-\mathrm{B}+\mathrm{B}-/ \mathrm{XB}-\mathrm{X}+$ $\begin{array}{lllll}\text { Latent inhibition } & \mathrm{X}- & \mathrm{B}+ & \mathrm{B}-/ \mathrm{XB}- & \mathrm{X}+\end{array}$

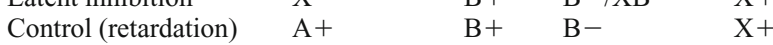

Experiment 3: Intramodal Differential Inhibition Differential inhibition $\mathrm{A}+/ \mathrm{B}-\quad \mathrm{X}+\mathrm{X}-/ \mathrm{XB}-\quad \mathrm{B}+$ \begin{tabular}{lllll} 
Control (retardation) & $\mathrm{A}+$ & $\mathrm{X}+\mathrm{X}-$ & $\mathrm{B}+$ \\
\hline
\end{tabular} Note-A, 500-msec, 2-kHz tone conditioned stimulus (CS); B, 500-msec, 8-kHz tone CS; X, 500-msec, 4-W light CS. “+” indicates a 25-msec unconditioned shock stimulus (US) was presented; "-" indicates no US. 

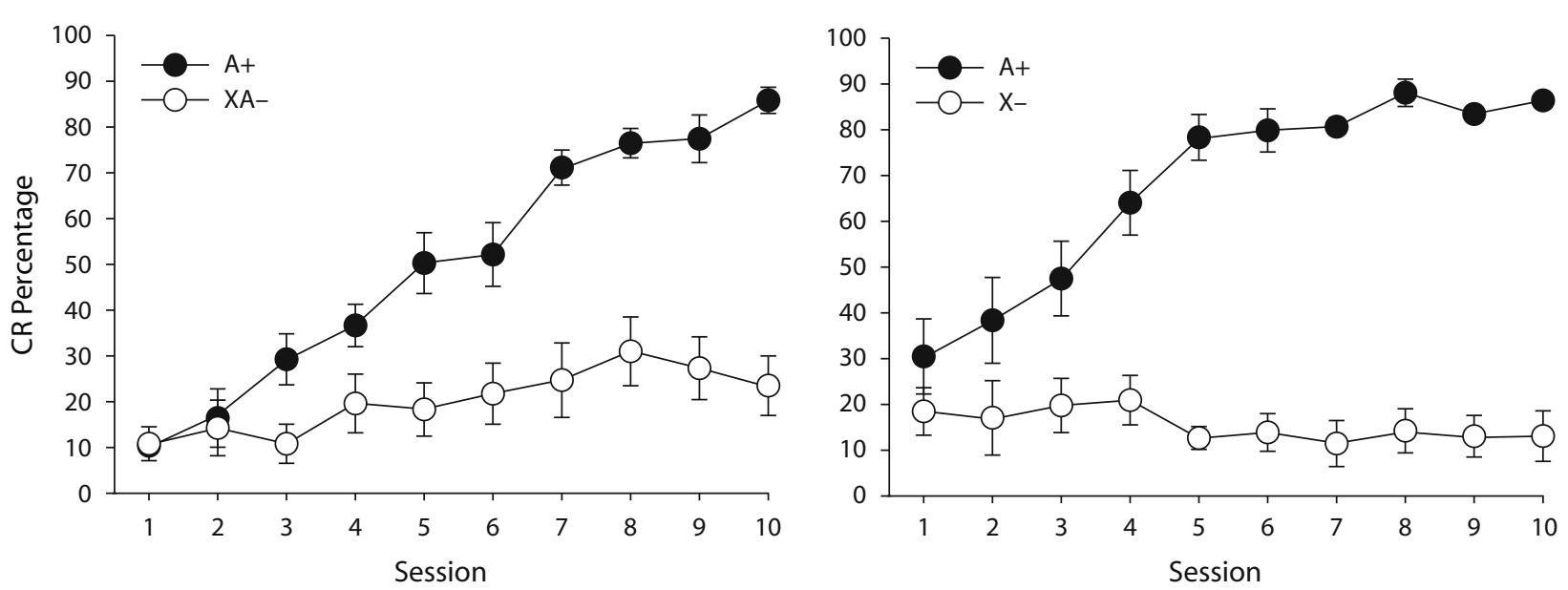

Figure 1. Mean percentages $( \pm S E M s)$ of conditioned responses (CRs) during Phase 1 training for rats in the Pavlovian conditioned inhibition or differential inhibition groups. Left: Pavlovian conditioned inhibition training included trials with a 2-kHz tone stimulus paired with the unconditioned stimulus (US; A+, black circles) and trials with a 2-kHz tone/light compound stimulus that was not paired with the US (XA-, white circles). Right: Differential inhibition training included trials with a 2-kHz tone stimulus paired with the US (A+, black circles) and trials with a light stimulus that was not paired with the unconditioned stimulus (X-, white circles).

as CRs. During CS-alone trials, responses that occurred between the end of the alpha period and the end of the CS were scored as CRs.

\section{Results and Discussion}

Pavlovian conditioned inhibition and differential inhibition training produced high levels of discrimination during initial training (Figure 1). The percentage of eyeblink CRs during $\mathrm{A}+$ trials increased across sessions, whereas the percentage of CRs during the nonreinforced trials (XAor $\mathrm{X}-$ ) remained relatively constant. By the 10th training session, the difference in CR percentage for reinforced and nonreinforced trials was greater than $60 \%$ for the groups that were given Pavlovian conditioned inhibition or differential inhibition training. The rats that were given Pavlovian conditioned inhibition training $(\mathrm{A}+/ \mathrm{XA}-)$ showed a lower percentage of CRs to the XB compound, relative to the $\mathrm{B}$ excitatory stimulus during the summation test (Figure 2, left). In contrast, the rats in the differential and latent inhibition groups did not show suppression of $\mathrm{CRs}$ to the $\mathrm{XB}$ compound during the summation test (Figure 2, left). However, both the Pavlovian conditioned inhibition and the differential inhibition training conditions resulted in inhibited acquisition of conditioning to the light CS (X), relative to the control groups during the retardation test (Figure 2, right).

An ANOVA for the Phase 1 data for the rats in the PAV and DIF groups did not produce a group $\times$ trial type $\times$ session interaction $[F(9,126)=1.59, p=.13]$, indicating that discrimination during Phase 1 was the same for both groups. Additional ANOVAs were conducted to determine the rate of discrimination during Phase 1 for each group. A within-subjects ANOVA for the PAV group revealed a significant interaction of the session and stimulus type factors $[F(9,63)=25.4, p<.001]$. A post hoc test (Tukey's honestly significantly difference [HSD]) showed that this effect was due to more responding to the $\mathrm{A}+$ than to the XAtrial types during Sessions $3-10$ ( $p<.05$, all comparisons).
A within-subjects ANOVA for the rats in the DIF group also showed a significant interaction between the trial type and the session factors $[F(9,63)=15.9, p<.001]$. A post hoc test (HSD) showed that this effect was due to more responding to $\mathrm{A}+$ trials than to $\mathrm{X}$ - trials during all 10 sessions of Phase 1 training ( $p<.05$, all comparisons).

The results from the summation test demonstrated that inhibition acquired to $\mathrm{X}$ was strong enough to attenuate responding to a separately trained excitatory stimulus (B) only for the rats in the PAV group. An ANOVA comparing performance for the rats in the PAV and the DIF groups during the summation produced a significant group $X$ trial type interaction $[F(1,14)=6.00, p<.03]$. A Tukey's HSD test showed that this effect was due to less responding to the XB trial type in the PAV group $(p<.05)$. A $t$ test showed that the rats in the LI group did not show a significant difference in responding to the $\mathrm{B}$ and $\mathrm{XB}$ trial types $[t(5)=1.72, p=.15]$.

Data from 1 rat in the PAV group was excluded from retardation test analysis because it did not complete the test. An ANOVA revealed a significant main effect of group for responding during the retardation test $[F(4,30)=12.7$, $p<.001]$. A follow-up test (HSD) showed that this effect was due to fewer CRs to $\mathrm{X}$ for the rats in the PAV and DIF groups, relative to the rats in the LI, CON1, and CON2 groups. There were no significant differences in CR percentage between the LI, CON1, and CON2 groups during the retardation test.

The results from the retardation test indicated that Pavlovian conditioned inhibition and differential inhibition procedures produced some inhibition to X (Figure 2, right). However, the results from the summation test indicated that the inhibition acquired to $\mathrm{X}$ was not equivalent. Pavlovian conditioned inhibition training was more effective at producing attenuated responding to a separately trained excitatory stimulus used in the summation test (Figure 2, left). This experiment also demonstrated that the inhibition 

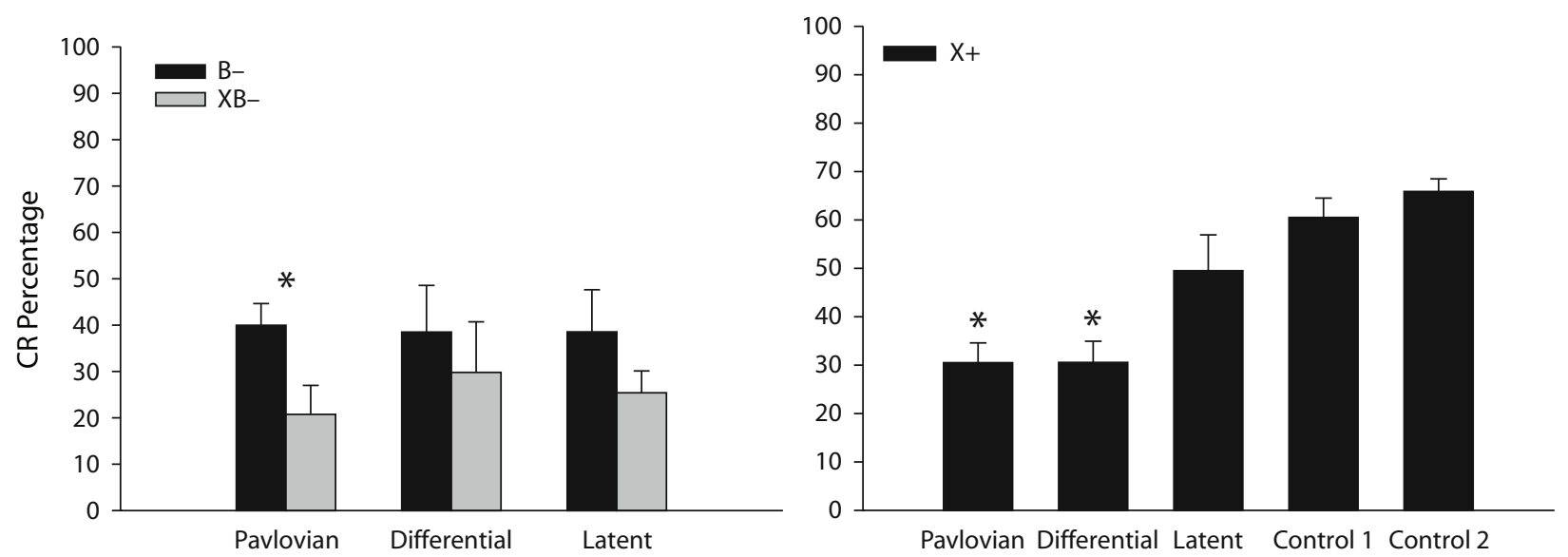

Figure 2. Mean percentages $( \pm S E M$ s) of conditioned responses (CRs) during the summation (Phase 3) and retardation (Phase 4) tests. Left: The summation test was conducted with an $8-\mathrm{kHz}$ tone stimulus $(\mathrm{B}-$, black bar) and an $8-\mathrm{kHz}$ tone/light compound stimulus (XB-, gray bar) that were not paired with the unconditioned stimulus for the rats in the Pavlovian, differential, and latent inhibition groups. Right: The retardation test was conducted with a light stimulus paired with the unconditioned stimulus $(\mathrm{X}+)$ trials for the rats in the Pavlovian, differential, latent inhibition, and retardation control groups. " "Significant differences.

observed in the PAV and DIF groups was not due to latent inhibition.

\section{EXPERIMENT 2}

Although the magnitude of discrimination in the rats given differential conditioning in Experiment 1 was high, it was possible that additional training may have resulted in inhibition during the summation test. Experiment 2 was designed to determine whether additional differential inhibition training would yield inhibitory learning strong enough to produce a summation effect. This finding would indicate that the amount of discrimination training, and not the magnitude of discrimination, plays an important role in inhibitory learning when differential conditioning procedures are used. Failure to obtain a summation effect might indicate that differential conditioning procedures, regardless of the amount of training and magnitude of discrimination, do not produce strong summation effects in rodent eyeblink conditioning. This outcome would suggest that discriminative training using Pavlovian conditioned inhibition procedures (Experiment 1) are necessary to produce a summation effect.

\section{Method}

The experimental design is illustrated in Table 1. The rats were assigned to a differential discrimination (DIF, $n=7$ ), latent inhibition (LI, $n=8)$, or retardation control (CON, $n=8)$ group. The conditioning procedure used in this experiment was the same as that in Experiment 1, except that Phase 1 consisted of 20 sessions of differential inhibition training.

\section{Results and Discussion}

As was seen in Experiment 1, differential inhibition training produced strong discriminative responding between the $\mathrm{A}+$ and $\mathrm{X}-$ trial types (Figure 3, left). The magnitude of the difference in CR percentage between $\mathrm{A}+$ and $\mathrm{X}-$ trials was asymptotic by the seventh training session and was maintained through the last training ses- sion. During the summation test, the rats given differential conditioning showed a lower percentage of CRs during trials with the $\mathrm{XB}$ compound, relative to trials with the previously reinforced B stimulus (Figure 3, middle). The rats in the latent inhibition control group did not show a reduction in responding during trials with the XB compound. Acquisition of conditioning to the putative inhibitor $(\mathrm{X})$ was weaker in the group that was given differential conditioning, relative to the control groups during the retardation test (Figure 3, right).

A within-subjects ANOVA revealed a significant interaction between the trial type and session factors for the CR percentages obtained from the rats in the DIF group during Phase $1[F(19,114)=134.3, p<.001]$. A Tukey's HSD test showed that significantly more responding occurred to $\mathrm{A}+$ trials than to $\mathrm{X}$ - trials during Sessions $2-10$ during Phase 1 training ( $p<.05$, all comparisons). An ANOVA using group and trial type as factors showed that the rats in the DIF group responded significantly more to $\mathrm{B}$ - trials than to $\mathrm{XB}-$ during the summation test $[F(1,13)=8.4, p<.02]$. The rats in the LI group did not respond differently between the $\mathrm{B}-$ and the $\mathrm{XB}-$ trial types. A separate ANOVA revealed a significant group effect for responding during the retardation test $[F(2,19)=$ 28.7, $p<.001]$. A follow-up test (HSD) showed that the rats in the DIF group responded significantly less to $\mathrm{X}$ than did the rats in the CON and LI groups $(p<.05$, both comparisons). There were no significant differences in CR percentage between the CON and the LI groups during the retardation test.

After extensive training, intermodal differential inhibition training produced inhibition similar to that observed with Pavlovian conditioned inhibition in Experiment 1. Experiments 1 and 2 demonstrated strong retardation effects for the rats in the DIF group, which indicated that differential training produced some inhibitory learning after only 10 sessions of training. However, extended discrimination training appeared to be necessary for $\mathrm{X}$ to ac- 

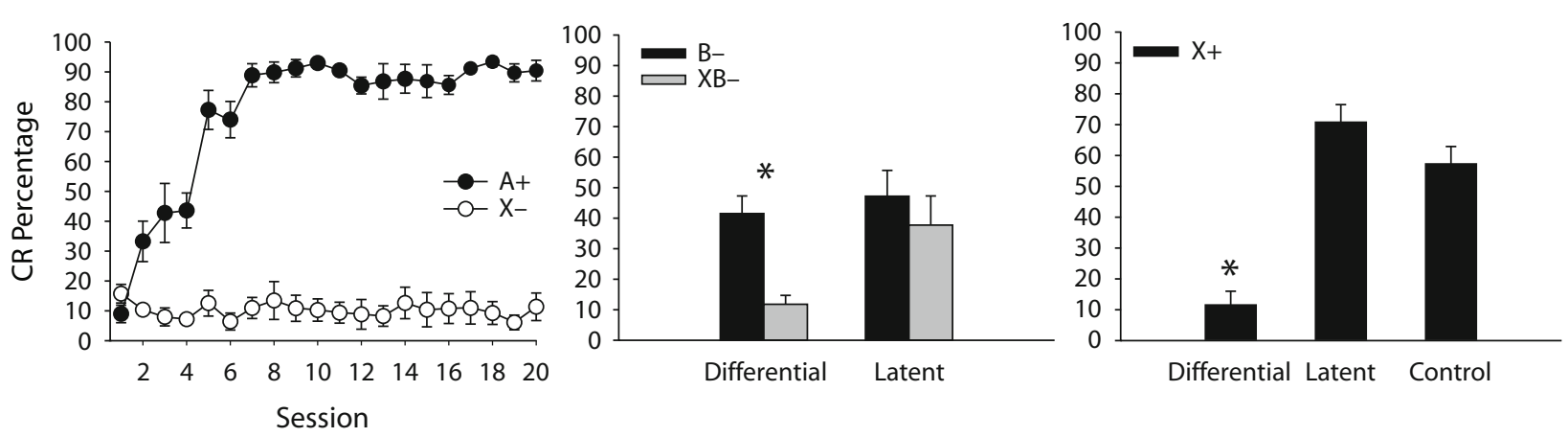

Figure 3. Mean percentages ( $\triangle S E M$ s) of conditioned responses (CRs) for the rats that received 20 sessions of intermodal differential inhibition training. Left: Differential inhibition training included trials with a $2-\mathrm{kHz}$ tone stimulus paired with the unconditioned stimulus $(\mathrm{A}+$, black circles) and trials with a light stimulus that was not paired with the unconditioned stimulus $(\mathrm{X}-$, white circles). Middle: The summation test was conducted with an 8-kHz tone stimulus (B-, black bar) and an 8-kHz tone/light compound stimulus (XB-, gray bar) that were not paired with the unconditioned stimulus for the rats in the differential inhibition and latent inhibition groups. Right: The retardation test was conducted with a light stimulus paired with the unconditioned stimulus $(\mathrm{X}+)$ trials for the rats in the differential inhibition, latent inhibition, and retardation control groups. " "Significant differences.

cumulate enough inhibitory strength to show a summation effect. Experiment 2 also replicated the finding that inhibition acquired to $\mathrm{X}$ was not due to latent inhibition.

\section{EXPERIMENT 3}

Experiment 2 showed that extended differential inhibition training with tone and light CSs is capable of producing inhibitory learning similar to that produced when Pavlovian conditioned inhibition procedures are used. The purpose of Experiment 3 was to determine whether the amount of training was a critical variable for establishing inhibition during intramodal discriminative conditioning. Intermodal discrimination involves stimulus differentiation on the basis of sensory modality, whereas intramodal discrimination involves stimulus differentiation based on a specific dimension within a sensory modality. The salient differences between different modality CSs may have been important for establishing the inhibitory learning observed in Experiments 1 and 2. Alternatively, stronger inhibition may occur when CSs from the same sensory modality are used, because the discrimination requires greater attention to a specific stimulus dimension (i.e., frequency). Experiment 3 was designed to assess whether intramodal differential discrimination using two auditory CSs during Phase 1 would be sufficient to produce behavioral inhibition to the nonreinforced tone CS. The rats in this experiment received either ten or twenty 100-trial sessions of auditory discrimination training $(\mathrm{A}+/ \mathrm{B}-)$, followed by summation and retardation tests.

\section{Method}

The experimental design is illustrated in Table 1. Differential discrimination rats (DIF) were given either $10(n=8)$ or $20(n=8)$ sessions of Phase 1 training. Retardation control rats $(\mathrm{CON})$ were assigned to either a $10-(n=5)$ or 20- $(n=4)$ session group. The tone CSs were counterbalanced in this experiment. The rats in the DIF groups received either ten or twenty 100 -trial sessions of differential discrimination training in Phase 1 , which consisted of $50 \mathrm{~T}_{1}+$ and $50 \mathrm{~T}_{2}$ trials. The rats in the CON groups were given either 10 or 20 sessions with $50 \mathrm{~T}_{1}+$ trials. Phase 2 training began the day after completing Phase 1. The DIF and CON rats received five 100-trial sessions of $\mathrm{L}+$ training. Phase 3 (summation test) consisted of $30 \mathrm{~L}-$ and $30 \mathrm{LT}_{2}$ - trials for the rats in the DIF groups, whereas the rats in the CON groups received $60 \mathrm{~L}-$ trials. Phase 4 training (retardation test) consisted of one 100-trial session of $\mathrm{T}_{2}+$.

\section{Results and Discussion}

Intramodal differential conditioning resulted in a higher percentage of CRs during trials with the reinforced tone $\mathrm{CS}(\mathrm{A}+)$, relative to trials with the nonreinforced tone CS (B-) (Figure 4, left column). The magnitude of the discrimination between $\mathrm{A}+$ and $\mathrm{B}-$ trials grew across training sessions, reaching a maximum at 17 sessions. Suppression of CRs occurred during the summation test in rats given 20 sessions of differential conditioning, but not in rats given 10 sessions of differential conditioning (Figure 4, middle column). Moreover, only the rats given 20 sessions of differential conditioning showed reduced acquisition of conditioning to the B stimulus, relative to the control group, during the retardation test (Figure 4, right column).

Separate within-subjects ANOVAs using CR percentages obtained during Phase 1 revealed significant interactions between the trial type and session factors for the rats given either 10 or 20 sessions of differential discrimination $[F(9,63)=4.9$ and $F(19,133)=15.4$, respectively; $p$ s $<.001]$. A follow-up test (HSD) showed that the rats given 10 sessions of differential intermodal discrimination responded more to A + trials than to B - trials on Sessions 4-10 (Figure 4, left) and that the rats given extended training with 20 sessions of discrimination responded more to $\mathrm{A}+$ than to $\mathrm{B}-$ trials on Sessions 4-6 and 8-20 (Figure 4 , left column) $(p s<.05)$. No significant differences were found in responding between the $\mathrm{X}-$ and the $\mathrm{XB}-$ trial types during the summation test for the rats given 10 sessions of Phase 1 training (Figure 4A, middle column). However, the rats given 20 sessions of Phase 1 training responded significantly more during $\mathrm{X}$ - than during $\mathrm{XB}-$ trials $[t(7)=3.64, p<.01$; Figure $4 \mathrm{~B}$, middle column]. Analyses of the retardation test showed that only the rats given 20 sessions of Phase 1 training responded signifi- 

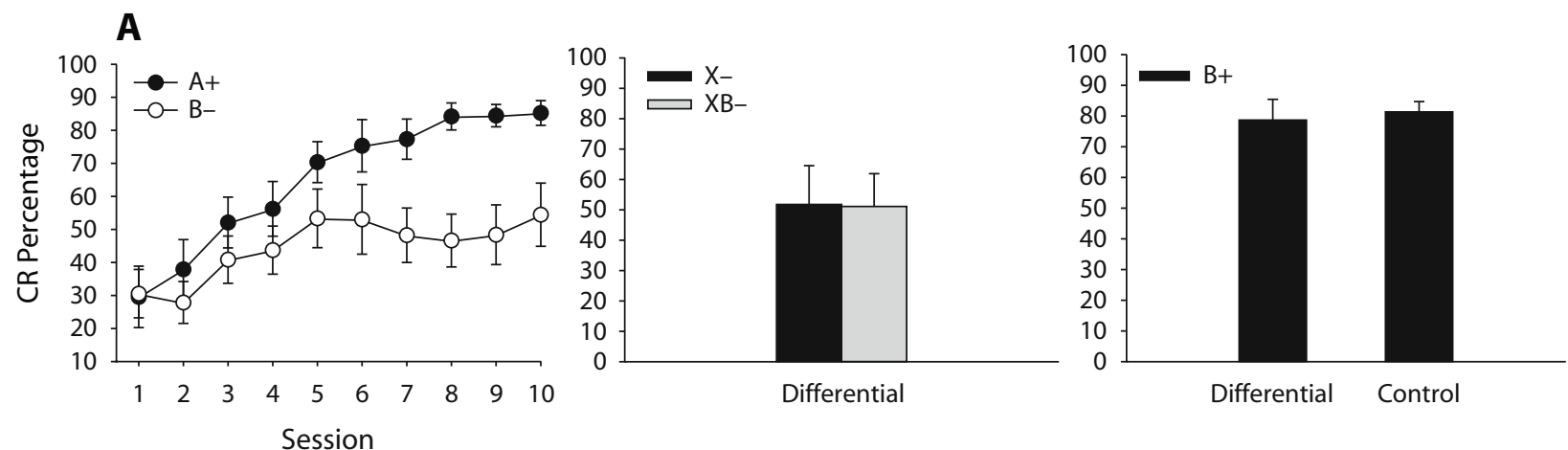

\section{B}
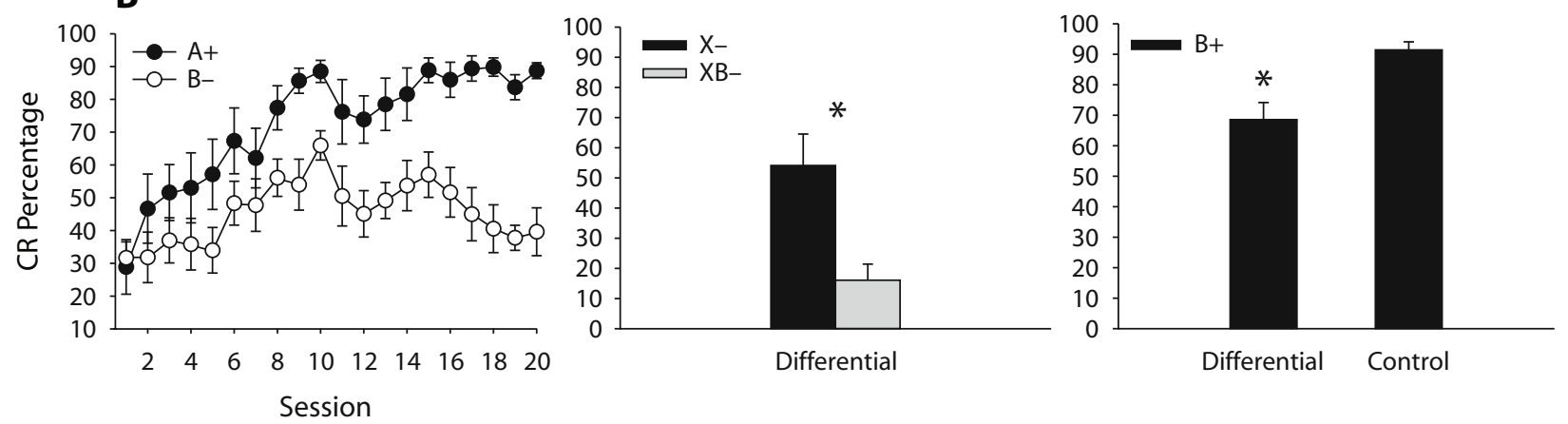

Figure 4. Mean percentages ( $\pm S E M$ s) of conditioned responses (CRs) for the rats that received 10 (A) or 20 (B) sessions of intramodal differential inhibition training. Left: Differential inhibition training included trials with a tone stimulus paired with the unconditioned stimulus $(A+$, black circles) and trials with a tone stimulus that was not paired with the unconditioned stimulus $(B-$, white circles). Middle: The summation test was conducted with a light stimulus (X-, black bar) and a light/tone compound stimulus (XB-, gray bar) that were not paired with the unconditioned stimulus. Right: The retardation test was conducted with a tone paired with the unconditioned stimulus $(\mathrm{B}+)$ trials for the rats in the differential inhibition and retardation control groups. ${ }^{*}$ Significant differences.

cantly less to $\mathrm{B}+$ than did the control rats $[t(10)=2.69$, $p<.01$; Figure 4, right column].

Intramodal differential inhibition training was capable of producing inhibition similar to Pavlovian conditioned inhibition, but only when extended discrimination training was given. In contrast to the results in Experiment 2, the present findings showed that 10 sessions of intramodal discrimination was not sufficient to produce a retardation effect. Stimulus generalization between the intramodal CSs may have affected the ability for the nonreinforced CS to accumulate enough inhibitory strength for retardation to occur after only 10 sessions of training. However, extended intramodal discrimination training overcame this difficulty and produced enough inhibitory strength to $\mathrm{B}$ to produce both summation and retardation effects.

\section{GENERAL DISCUSSION}

Experiment 1 used summation and retardation tests to examine inhibitory eyeblink conditioning with Pavlovian conditioned inhibition $(\mathrm{A}+/ \mathrm{XA}-)$ and differential inhibition $(\mathrm{A}+/ \mathrm{X}-)$ procedures. After 10 sessions of training, Pavlovian conditioned inhibition training resulted in more inhibition than did differential inhibition training. The rats in the Pavlovian conditioned inhibition and differential inhibition groups showed strong retardation effects, but only the rats in the Pavlovian conditioned inhibition group showed a summation effect. When differential inhibition training was increased to 20 sessions in Experiment 2, strong summation and retardation effects were obtained. Intramodal differential inhibition $(\mathrm{A}+/ \mathrm{B}-)$ training conducted with two tone CSs in Experiment 3 was not effective for producing summation or retardation effects after 10 sessions of training. However, summation and retardation effects were obtained when intramodal differential inhibition training was increased to 20 sessions. The present experiments demonstrated that the amount of training, not the magnitude of discrimination, is an important factor for determining the strength of differential inhibition. Extensive differential inhibition training produced a degree of inhibition similar to that observed in Pavlovian conditioned inhibition.

Experiments 1 and 2 also showed that extensive CS preexposure produced no inhibitory conditioning, as indicated by the summation and retardation tests. This finding suggests that Pavlovian conditioned inhibition and differential inhibition in eyeblink conditioning are not due to latent inhibition-like effects. This finding is consistent with the hypothesis that inhibition accumulates most strongly when an inhibitor is presented when there is an expectation of reinforcement (Wagner \& Rescorla, 1972).

Differences in performance were observed between intermodal and intramodal differential conditioning during 
the summation and retardation tests after 10 training sessions. When differential inhibition training was conducted with light and tone CSs for 10 training sessions, a strong retardation effect was obtained. In contrast, 10 sessions of differential inhibition training with two tone CSs did not produce a retardation effect. However, with extensive intramodal discriminative conditioning, differential inhibition training produced summation and retardation effects. These results suggest that the relatively salient differences between stimuli from different sensory modalities during intermodal discrimination learning played a more important role in acquisition of inhibitory conditioning than did increased attention to a stimulus dimension (i.e., tone frequency) during intramodal discrimination learning.

A previous study did not show differences in inhibitory conditioning in rabbits given Pavlovian conditioning inhibition or differential inhibition training (Mahoney et al., 1975). In contrast, after 10 sessions of training in Experiment 1 in the present study, only the rats given Pavlovian conditioned inhibition training showed a summation effect. One possible reason for the different results may be that in the present study, different stimulus modalities were used during the summation tests. Inhibition acquired to the auditory CS used during differential inhibition training in Mahoney et al.'s study may have generalized to the white noise CS used during the summation test. This possibility makes it difficult to directly compare the results obtained for rabbits given Pavlovian conditioned inhibition and those given differential inhibition. The present experiments avoided this problem by conducting summation tests with different modality stimuli. Importantly, previous experiments have reported little immediate cross-modal generalization in eyeblink in rats and NM conditioning in rabbits (Campolattaro \& Freeman, 2006; Kehoe, 1988; Kehoe, Morrow, \& Holt, 1984; Schreurs \& Kehoe, 1987; Weidemann \& Kehoe, 2005). The summation tests used in the present experiments were, therefore, more suitable for comparing Pavlovian conditioning inhibition and differential inhibition.

In summary, the present experiments used rodent eyeblink conditioning to demonstrate that increased differential inhibition training produces inhibition similar to that observed in Pavlovian conditioned inhibition. Additional experiments are necessary to determine the generality of these findings.

\section{AUTHOR NOTE}

This research was supported by National Institute for Mental Health Grant MH065483. Correspondence concerning this article should be addressed to J. H. Freeman, Department of Psychology, University of Iowa, E11 Seashore Hall, Iowa City, IA 52242 (e-mail: john-freeman@, uiowa.edu).

\section{REFERENCES}

Campolattaro, M. M., \& Freeman, J. H. (2006). Perirhinal cortex lesions impair feature-negative discrimination. Neurobiology of Learning \& Memory, 86, 205-213.
Couvillon, P. A., Ablan, C. D., \& Bitterman, M. E. (1999). Exploratory studies of inhibitory conditioning in honeybees (Apis mellifera). Journal of Experimental Psychology: Animal Behavior Processes, 25, 103-112.

Freeman, J. H., JR., Halverson, H. E., \& Poremba, A. (2005). Differential effects of cerebellar inactivation on eyeblink conditioned excitation and inhibition. Journal of Neuroscience, 25, 889-895.

Freeman, J. H., JR., \& Nicholson, D. A. (1999). Neuronal activity in the cerebellar interpositus and lateral pontine nuclei during inhibitory classical conditioning of the eyeblink response. Brain Research, 833, 225-233.

Jones, D., \& GonZalez-Lima, F. (2001). Associative effects of Pavlovian differential inhibition of behaviour. European Journal of Neuroscience, 14, 1915-1927.

Kenoe, E. J. (1988). A layered network model of associative learning: Learning to learn and configuration. Psychological Review, 95, 411-433.

Kehoe, E. J., Morrow, L. D., \& Holt, P. E. (1984). General transfer across sensory modalities survives reductions in the original conditioned reflex in the rabbit. Animal Learning \& Behavior, 12, 129-136.

Mahoney, W. J., Kwaterski, S. E., \& Moore, J. W. (1975). Conditioned inhibition of the rabbit's nictitating membrane response as a function of CS-US interval. Bulletin of the Psychonomic Society, $\mathbf{5}$, 177-179.

Nicholson, D. A., \& Freeman, J. H., JR. (2002). Neuronal correlates of conditioned inhibition of the eyeblink response in the anterior interpositus nucleus. Behavioral Neuroscience, 116, 22-36.

Nolan, B. C., \& Freeman, J. H., JR. (2005). Purkinje cell loss by OX7saporin impairs excitatory and inhibitory eyeblink conditioning. Behavioral Neuroscience, 119, 190-201.

Nolan, B. C., \& Freeman, J. H., [Jr.] (2006). Purkinje cell loss by OX7-saporin impairs acquisition and extinction of eyeblink conditioning. Learning \& Memory, 13, 359-365.

Pavlov, I. P. (1927). Conditioned reflexes: An investigation of the physiological activity of the cerebral cortex (G. V. Anrep., Trans. \& Ed.). London: Oxford University Press.

Rescorla, R. A. (1969). Pavlovian conditioned inhibition. Psychological Bulletin, 72, 77-94.

RESCORLA, R. A. (1982). Some consequences of associations between the excitor and the inhibitor in a conditioned inhibition paradigm. Journal of Experimental Psychology: Animal Behavior Processes, 8, 288-298.

Rescorla, R. A., \& LoLordo, V. M. (1965). Inhibition of avoidance behavior. Journal of Comparative \& Physiological Psychology, 59, 406-412.

Schreurs, B. G., \& Kehoe, E. J. (1987). Cross-modal transfer as a function of initial training level in classical conditioning with the rabbit. Animal Learning \& Behavior, 15, 47-54.

Urcelay, G. P., \& MilleR, R. R. (2006). A comparator view of Pavlovian and differential inhibition. Journal of Experimental Psychology: Animal Behavior Processes, 32, 271-283.

WAGNeR, A. R., \& REsCoRla, R. A. (1972). Inhibition in Pavlovian conditioning: Applications of a theory. In R. A. Boakes \& M. S. Halliday (Eds.), Inhibition and learning (pp. 301-366). London: Academic Press.

Weidemann, G., \& Kehoe, E. J. (2005). Stimulus specificity of concurrent recovery in the rabbit nictitating membrane response. Learning \& Behavior, 33, 343-362.

Williams, D. A., Travis, G. M., \& Overmier, J. B. (1986). Withincompound associations modulate the relative effectiveness of differential and Pavlovian conditioned inhibition procedures. Journal of Experimental Psychology: Animal Behavior Processes, 12, 351-362.

(Manuscript received November 9, 2007; revision accepted for publication January 15,2008 .) 